\title{
When Unnecessary Repairs Become Necessary: The Case of Nasal Insertion in Standard Mandarin Loanwords
}

\author{
Ho-Hsin Huang and Yen-Hwei Lin \\ Michigan State University
}

\section{Introduction}

This paper investigates how English intervocalic nasals are adapted into Standard Mandarin (SM) loanwords and explains when and why seemingly unnecessary nasal insertion occurs. Nasal consonants in English have several adaptation forms in SM loanwords. ${ }^{1}$ The most common form is a faithful mapping in syllable onset position, e.g. Nate $\rightarrow$ [nai. $t^{h}$ :] , Mark $\rightarrow$ [ma: $k^{h} \gamma:$ ]. Since SM does not allow [m] in coda position, a coda [m] in English has to change to [n] or [n] in SM loanwords, e.g. Pam $\rightarrow$ [p $\left.p^{h} a n\right]$, Thompson $\rightarrow\left[t^{h} a \eta\right.$.pu:szn]. What is of interest is that an English intervocalic nasal is adapted in three different ways: (i) faithful one-to-one mapping, e.g. Lina $\rightarrow$ [li:.na:], (ii) one-to-two mapping with nasal insertion, e.g. Benedict $\rightarrow$ [pən.ni:ti:kr:.tr:], and (iii) variable adaptation with or without nasal insertion, e.g. Tiffany $\rightarrow$ [ti:fan.nei] [ti:fu:.ni:].

In loanword adaptation, various repair strategies are used to produce licit adapted forms, but there are cases in which an unnecessary repair is made even when a direct mapping without any repairs would have produced a licit adapted form (Kang 2011: 2260). Nasal insertion in SM loanwords is one such case since there is no phonotactically illicit structure in need of repair. That is, an intervocalic nasal in English can be faithfully mapped as a single nasal consonant in SM without incurring a phonotactic violation. This paper proposes a combined phonological and phonetic account of when an English intervocalic nasal singleton is adapted with unnecessary nasal insertion, (e.g. Daniel $\rightarrow\left[\right.$ tan.ni:.əu]) in SM loanwords, when it is not (e.g. Bruno $\rightarrow\left[\right.$ [pu:lu:. $\left.n^{w} o\right]$ ), and when variation occurs (e.g. Tiffany $\rightarrow$ [ti:fan.nei] [ti:fu.:ni:]). Taking data from a dictionary corpus, we identify two conditions in the English source words that typically trigger nasal insertion in SM loanwords: (i) the pre-nasal vowel being lax and non-high and (ii) the pre-nasal vowel bearing the primary stress. When the pre-nasal vowel is an unstressed schwa or a reduced vowel in English, the adapted words can appear with or without nasal insertion.

In the next section, we briefly review consonant gemination in three loanword systems which share some similarities with nasal insertion in SM loanwords. The SM data and generalizations are presented in $\S 3$. In $\S 4$, we propose an analysis of the three adaptation patterns of English intervocalic nasals. The final section gives discussion and conclusion.

\footnotetext{
${ }^{1}$ The adaptation of English intervocalic velar nasals is not discussed in this paper as we have only a few examples in the corpus.
} 


\section{Studies on consonant gemination}

Nasal insertion in SM loanwords to some extend is similar to consonant gemination in several languages. Consonant gemination is one repair strategy in adapting English words into Japanese (Lovins, 1975, Kawahara 2007; Kubozono, Itô, \& Mester 2008, Shirai 1999). It is also found in Italian (Repetti 2009) and Cantonese (Yip 1993: 274) loanwords. The conditions that trigger nasal insertion in SM loanwords overlap with those in consonant gemination.

Lovins (1975) shows that Japanese loanwords from English often undergo gemination when the source word contains a stressed short vowel and an obstruent in word-final position and that intervocalic consonants sometimes undergo gemination in loanwords. Lax vowels in English are adapted into Japanese short vowels. Tense vowels are adapted as long vowels and block gemination. Her discussion is mainly centered on the stress and the quality of the source vowels.

Shirai (1999), by examining a corpus with 3,399 Japanese loanwords adapted from English, also concludes that most geminates are from three source environments: (i) when a consonant is a singleton in word-final position of a source word; (ii) when a consonant follows a stressed syllable; (iii) the consonant is considered an ambisyllabic consonant. In all environments, gemination requires two major conditions: lax vowel and singleton conditions. The lax vowel condition means the vowel preceding the geminate has to be a lax vowel. The singleton condition means the geminating consonant cannot be in a consonant cluster. She further concludes that voiceless consonants are geminated in most cases and word-final consonants get geminated more often than ambisyllabic consonants.

Repetti (2009) examines gemination in English-based loanwords in American varieties of Italian, e.g. coal $\rightarrow$ ['kolle], and bushel $\rightarrow$ ['buffolo]. She argues that many factors play a role in gemination, such as the segmental inventory of the recipient language, the structure of the stressed syllables, and the phonetic details of the source words, and that speakers try to preserve the syllable structure of the source form by gemination, specifically the moraicity of final consonants. That is, if the stressed syllable in the source language is bimoraic, gemination applies in the loanwords. She also takes Peperkamp and Dupoux's (2003) view that the speakers are able to interpret the fine acoustic detail of the vowel and consonant length of their own phonological system. For example, a consonant that follows a long vowel is phonetically shorter than if it follows a short vowel. To account for American-Italian loanword gemination, she maintains that a combination of both phonological and phonetic factors needs to be taken into consideration.

Duanmu (2000/2007) argues that the minimal syllable in Cantonese is $[\mu \mu] \sigma$, i.e., in an open syllable, all vowels have to be long, for example, flower [fa:], *[fa]. Yip (1993: 274) agrees with Duanmu's claim on Cantonese syllable weight and concludes that Cantonese bimoraic syllable structure is supported by loanword phonology. English short, open syllables surface as closed syllables in Cantonese by gemination of the following onset, e.g. copy [kapi] $\rightarrow$ [kappi] $]^{2}$; however, long open syllables in English do not trigger gemination in Cantonese loanwords (Yip 1993, p. 273). She further concludes that consonant gemination in Cantonese loanwords can be understood as the result of the phonological need for a bimoraic syllable.

\footnotetext{
${ }^{2}$ Yip claims that the low vowel is short. However, House (1961) and Umeda (1975) show that English low back vowel is phonetically long.
} 
In sum, nasal insertion in SM loanwords and consonant gemination in other loanword systems share similar patterns. Unlike consonant gemination in those systems, nasal insertion in SM loanwords is not the only strategy to remedy syllable structure problems since besides nasal insertion, vowel lengthening can also repair light syllables in English when they are adapted. The question is then why nasal insertion is preferred in some SM loanwords but not others. In this paper, we explore perceptual factors in addition to phonological ones.

\section{SM loanword data and generalizations}

The current corpus data are collected from Appendix I, a list of common British and American names, of A New English-Chinese Dictionary (1988). The corpus consists of around 2400 British and American male and female names; more than 1600 nasal consonants in different syllable positions are examined. We also found some words outside the dictionary ${ }^{3}$ with a prenasal low back [a] that are not adapted with nasal insertion even though they fulfill both the vowel type and stress location conditions for nasal insertion.

By looking only at intervocalic nasal consonants in English, the data from the corpus can be grouped into three types: adaptation in SM loanwords with nasal insertion, those without insertion, and those that are variably adapted with or without nasal insertion. Each type consistently occurs under specific conditions. The two main factors that condition the adaptation of nasal insertion in SM loanwords are the prenasal vowel quality/quantity and the location of stress ${ }^{4}$. The prenasal vowel in English has to be lax and non-high and bears the primary stress. The examples in the three subcategories in (1) illustrate how intervocalic nasal singletons in English are adapted with nasal insertion in SM loanwords.

(1) English intervocalic nasal singletons adapted with nasal insertion in SM loanwords.
a. English ['VnV] $\rightarrow \quad \mathrm{SM}[\mathrm{VnnV}]$
Diana [tai.an.na:]
Benedict $\quad$ ponn.ni..ti:.kr:.tr:]
b. English ['VnV] $\rightarrow \quad \mathrm{SM}[\mathrm{VynV}]$
Donald [ $\mathrm{t}^{\mathrm{h}}$ an.na:.tr: $]$
Sauna [san.na:]
c. English [ $\mathrm{VmV}] \rightarrow \quad \mathrm{SM}[\mathrm{VnmV}]$ or $[\mathrm{VymV}]$
Sammy [san.mi:]
Thomas [ $\quad\left[\mathrm{t}^{\mathrm{h}}\right.$ an.ma:.sì: $]$

The intervocalic nasal consonants in English are adapted from [n] to [n.n] or [y.n] and from [m] to [n.m] or [y.m]. The inserted coda nasal in SM loanwords is either identical to its second nasal, as in (1a), or agrees in

\footnotetext{
${ }^{3}$ The English low back $[\mathrm{a}]$ cases were found on blogs, websites and public media. They are surnames, country names, and foreign imported objects.

${ }^{4}$ Shih (2013) independently observed the same phenomena based on a different corpus: i.e., English vowel types and stress location condition nasal insertion in SM loanwords.
} 
frontness and backness with the preceding stressed non-high vowel in English, as in (1b-c) (cf. Hsieh, Kenstowicz \& Mou (2009)).

However, not all intervocalic nasal consonants are adapted with insertion in SM loanwords. The examples in (2)-(4) show that nasal insertion does not appear (i) when the prenasal stressed vowel in English is high or tense/long, or is a diphthong, (ii) when the prenasal vowel is unstressed and the postnasal vowel is stressed, and (iii) when the prenasal vowel in English is a stressed low back [a] in a trisyllabic unstressed-stressed-unstressed word.

(2) The prenasal stressed vowel in English is high or tense/long, or is a diphthong.

$\begin{array}{lll}\text { English ['V:N] } \rightarrow & \text { SM [VN] } \\ \text { Bruno } & \text { [pu:.lu:.nwo] } \\ \text { Sony } & & \text { [s'o.ni: }]\end{array}$

(3) The prenasal vowel is unstressed and the postnasal vowel is stressed.

$\begin{array}{ll}\text { English [VN'V] } \rightarrow & \text { SM [VNV] } \\ \text { Bonita } & \text { [p }{ }^{\mathrm{w}} \text { o.ni..ta:] } \\ \text { Denise } & \text { [ti..ni..si:] }\end{array}$

(4) The prenasal vowel is a stressed low back [a] in a trisyllabic unstressed-stressed-unstressed word.

$\begin{array}{lll}\text { English ['aNV] } \rightarrow & \text { SM [a.NV] } \\ \text { Cabana } & \text { [k } \mathrm{k}^{\mathrm{h}} \text { a:.pa:.na] } \\ \text { Astana } & & \text { [a:.sit..tha:.na:] }\end{array}$

In the 2400 proper names, there are 119 cases in which intervocalic nasal consonants in English are adapted with nasal insertion in SM loanwords. Within the words with nasal insertion, four non-high, lax vowels in English trigger the insertion in SM loanwords: $[\mathfrak{x}],[0],[\varepsilon]$, and $[\Lambda]^{5}$. Moreover, the lower the vowel is, the higher the chance there is for insertion in SM loanwords. There are some exceptions where high and long vowels trigger nasal insertion; however, they are very few in number. The percentage of unstressed prenasal vowels that trigger insertion is very low as well. Table 1 shows the numbers and the percentage of different types of vowels that trigger nasal insertion and of insertion that occurs when either the vowel type condition or stress location condition is violated.

\begin{tabular}{|c|c|c|c|c|c|c|c|}
\hline & \multicolumn{4}{|c|}{ Non-high, lax } & \multicolumn{2}{|c|}{ High/Tense } & Unstressed \\
\hline Vowels & $æ$ & 0 & $\varepsilon$ & $\Lambda$ & I & $\begin{array}{c}\text { Tense } \\
\text { vowels }\end{array}$ & $\begin{array}{l}\text { Unstressed } \\
\text { vowels }\end{array}$ \\
\hline Number & 42 & 30 & 29 & 8 & 3 & 4 & 3 \\
\hline Percentage & $35.29 \%$ & $25.21 \%$ & $24.36 \%$ & $6.72 \%$ & $2.52 \%$ & $3.33 \%$ & $2.52 \%$ \\
\hline Subtotal & \multicolumn{4}{|c|}{$91.16 \%(109 / 119)$} & \multicolumn{2}{|c|}{$5.9 \%(7 / 119)$} & $2.52 \%(3 / 119)$ \\
\hline
\end{tabular}

Table 1. Nasal insertion in SM loanwords with different vocalic contexts and stress condition in the English source.

\footnotetext{
${ }^{5}$ Compared to other lax vowels, $[\Lambda]$ triggers less insertion in SM loanword probably because it can be treated as a tense vowel in English or SM speakers perceive it as being tense.
} 


\section{Data analysis}

4.1. Phonetic and phonological factors We propose that unnecessary nasal insertion in SM loanwords is needed to match the perceived English inputs. As suggested above, two main conditions trigger nasal insertion: prenasal vowel quality/quantity and stress location. To fulfill the prenasal vowel quality/quantity condition, the prenasal vowel in the English source word has to be a non-high lax/short vowel. By inserting a nasal consonant, the SM output creates a closed syllable so that there is a better match of vowel duration with the short or lax vowel in the English source. Moreover, Solé's (1992) and Krakow's (1994) research on vowel nasalization suggest that nonhigh vowels in nasal contexts, e.g. CVN in English, exhibit more nasalization than high nasalized vowels; therefore, inserting a nasal coda after a stressed non-high vowel produces a better match in phonetic detail. Durvasula, Huang and Merrill (2013) show that the ambisyllabic nasal consonants pattern with word-medial codas. Therefore, we suggest that in the loanword adaptation process, SM speakers perceive the phonetic details of the duration and nasality of the vowel in the English source word, and insert an extra nasal consonant to better approximate the phonetic details. However, as the examples in (2)-(4) show, nasal insertion does not apply when the English prenasal vowel is either a tense vowel or a diphthong or when the vowel is the phonetically longest low back vowel, [a] (House 1961; Umeda 1975) in a trisyllabic word. These vowels may have already mapped the required SM syllable duration (Duanmu 2000/2007); therefore, the adaptation process does not undergo the insertion process.

To fulfill the stress location condition, the prenasal vowel needs to bear the primary stress. Stressed syllables in English have longer duration than stressless ones. However, in SM, except for neutral toned syllables, every syllable is roughly the same in syllable duration and syllable weight (Duanmu 2000/2007). Therefore, inserting a nasal coda helps preserve the longer perceived duration from the stressed syllables in English and preserve the syllable weight in SM by compensating for a lax vowel in English stressed syllables (cf. the analysis of consonant gemination in Cantonese by Yip (1993) mentioned in §2).

The insertion process can also be explained from the perspective of ambisyllabicity. In the present case, the intervocalic nasal consonants are ambisyllabic in English. Hayes (2009) argues that ambisyllabic consonants are dominated by more than one syllable, as illustrated in Figure 1. The stressed syllable wants to have more segments, while the stressless one wants fewer, and meanwhile, all syllables want to have onsets. He further argues that this representation would account for the ambiguous intuition speakers have concerning the syllabification of such words. In our case, when the ambisyllabic consonant is a nasal consonant, syllabification seems to be affected by the degree of vowel nasalization and/or vowel duration on the prenasal vowel (cf. Hayes 2009 vs. Durvasula, Huang and Merrill 2013; see also footnote 6 below).

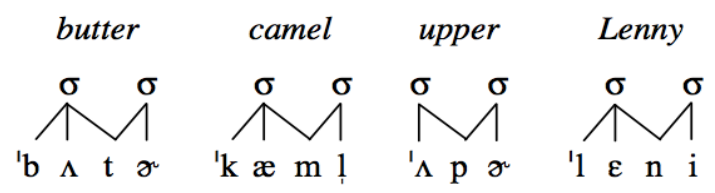

Figure 1: Ambisyllabic consonants are dominated by more than one syllable (Hayes 2009:1).

Hayes also argues that the division of English syllables is not always unclear but when a stressed vowel follows a consonant, syllabification is clear, e.g. balloon [bə.'lun]. His analysis on ambisyllabicity and on clear syllable 
division can account for nasal insertion in SM loanwords. The derivation in Figure 2 illustrates how an intervocalic nasal is adapted with nasal insertion in a SM loanword. In Figure 3, the English intervocalic nasal consonant does not get adapted with an extra nasal in the SM loanword when it is followed by a stressed vowel.

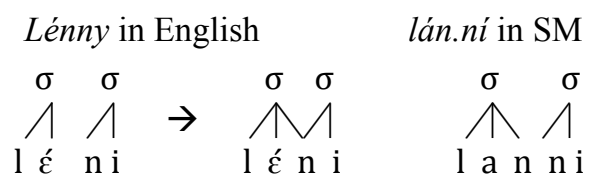

Figure 2: When the intervocalic nasal is ambisyllabic

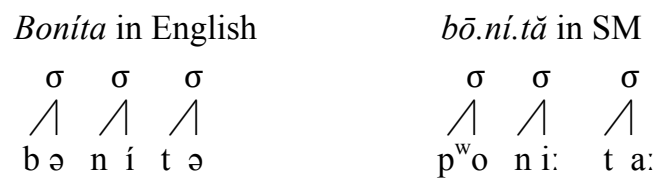

Figure 3: When the intervocalic nasal is not ambisyllabic

Interestingly, variable adaptation appears in some examples. In the examples in (5), the intervocalic nasal in English is variably mapped to either one or two nasals in SM loanwords.

(5) Variation in nasal insertion

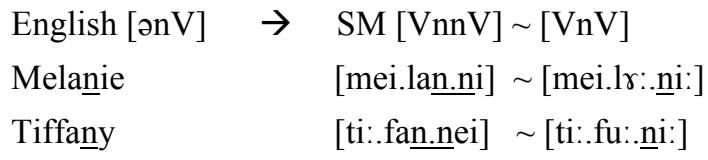

We attribute the variation to the vowel quality of the prenasal vowel in English. Variation in nasal insertion appears when the English prenasal vowel is a schwa or an unstressed reduced vowel [I] in the middle of a trisyllabic stressed-unstressed-unstressed English word. The fact that the stressless schwa or reduced vowel often triggers variation in nasal insertion can probably be accounted for by phonetic and phonological factors as well. The schwa is the least specified phonologically, and is phonetically the shortest and most variable vowel in English. This is likely to make a [Ca] syllable a good candidate for duration compensation through the nasal insertion process; on the other hand, an unstressed syllable may not be prominent enough to make it necessary for nasal insertion in SM loanwords. The indeterminacy can then lead to adaptation variability.

4.2. OT analysis We assume the Perceptual and Operative Levels in loanword phonology proposed by Silverman (1992) and adopt Yip's MIMIC approach for the analysis. The MIMIC constraints (Yip 2006: 956) are a set of loanword-specific constraints that enforce faithfulness to the percept. According to Yip, the input to the grammar of the borrowing language is the native percept of the sounds of the source language filtered by the perceptual module (Silverman 1992; Yip 1993).

Based on our data, although the perceived form may contain the phonology of the source language as well, by following Silverman's (1992) loanword model, we assume that the input is not a phonological representation but acoustic signals filtered by the adaptors' native perceptual constraints. That is, the SM speakers map the perceived 
foreign sound to the closet native sound, e.g., when [I] enters the Perceptual Level, SM speakers perceive it as [i] since [i] is the only high front vowel in SM. In the present analysis, our main concern is not the adaptors' L2/English knowledge. The inputs in all the following OT tableaux are the perceived sounds at the Perceptual Level, where the native segmental inventory and other acoustic details constrain the representation of perceived segments. At the Operative Level, the perceived segments undergo true phonological operations that are triggered by the native phonotactic constraints. Although some studies argue that orthographic inputs may influence loanword adaptation (cf. LaCharite \& Paradis 2005; Smith 2006; Vendelin \& Peperkamp 2006), the current analysis focuses on the phonetic and phonological factors. The relevant constraints for the analysis are proposed in (6).

\section{(6) Constraints}

a. OK- $\sigma$ : Only permissible syllables in SM are allowed (cf. Yip 2006: 956).

b. MIMIC $\mathrm{V}_{\mathrm{NASAL}}$ : Corresponding vowels in the input and the output have similar nasal quality.

c. MIMIC $\mathrm{V}_{\text {DURATION: }}$ : Corresponding vowels in the input and the output have similar duration.

d. MIMIC $\mathrm{V}_{\text {BACK }}$ : Corresponding vowels in the input and the output have the same backness (cf. Lin 2008: 372).

e. DEP-IO: No insertion of any segment.

Yip (1993) proposed the OK- $\sigma$ constraint as a package of constraints that can immediately rule out all the candidates with impermissible syllable structures. In this analysis, the output might not perfectly match with the input due to some deviation in vowel adaptation (cf. Lin 2008). The tableau in (7) illustrates how the optimal output of Bruno is produced.

(7) Adaptation of Bruno ['brunov]

\begin{tabular}{|c|c|c|c|}
\hline /'bru:noø/ & $\mathrm{OK}-\sigma$ & MIMIC $V_{\text {DURATION }}$ & DEP-IO \\
\hline a. [b.u:.n" ${ }^{\mathrm{w}} \mathrm{o}$ ] & *! (br) & & \\
\hline b. [blu:. $\mathrm{n}^{\mathrm{w}} \mathrm{o}$ ] & $* !(\mathrm{bl})$ & & \\
\hline c. [bu:lu:.n $\left.{ }^{\mathrm{w}} \mathrm{o}\right]$ & & & $*(\mathrm{u})$ \\
\hline d. [bu:.lun. ${ }^{\mathrm{w}} \mathrm{o}$ ] & & *! (too short) & $* *(\mathrm{u})(\mathrm{n}$ \\
\hline
\end{tabular}

We assume that at the Perceptual Level, SM speakers perceive the vowels as long [u:] and [oซ] as they are tense/long and stressed; therefore, the input of the tableau is /'bıu:now/. Candidates (7ab) are ruled out by OK- $\sigma$. According to Miao (2005), English [x] is most frequently mapped to [1] in SM, hence [1] is picked as the match in the output. MiMIC $\mathrm{V}_{\text {DURATION }}$ rules out candidate (7d) because the vowel in [lun] is shorter. Maddieson (1984: 89) argues for the existence of certain phonetic cues to syllabification: Vowels are universally shorter in a closed syllable than in an open syllable. This analysis therefore claims that the best output match for [ru:] in the perceived input should be [lu:] in an open syllable without nasal insertion.

Tableau (8) shows an example of an unnecessary repair, i.e. nasal insertion. Both the phonetic and phonological accounts proposed in $\S 4.1$ can fulfill the MIMIC $V_{\text {NASAL }}$ constraint since this intervocalic nasal can be considered 
ambisyllabic due to the nasalization on the prenasal vowel (Hayes 2009). ${ }^{6}$ MIMIC $\mathrm{V}_{\mathrm{BACK}}$ is introduced in tableau (8) to show that a faithful match of vowel backness is important (Lin 2008).

(8) Adaptation of Lenny [' 'lẽni]

\begin{tabular}{|c|c|c|c|c|c|}
\hline /'lẽni:/ & $\mathrm{OK}-\sigma$ & MIMIC $\mathrm{V}_{\text {DURATION }}$ & MIMIC $V_{\text {BACK }}$ & MIMIC $V_{\text {NASAL }}$ & DEP-IO \\
\hline a. $\left[\mathrm{la}_{\mathrm{c}}: \mathrm{ni}:\right]$ & & $*$ (too long) & & $*$ & \\
\hline b. [len.ni:] & $* !(\operatorname{l\varepsilon n})$ & & & & $*(\mathrm{n})$ \\
\hline c. [lei.ni:] & & *! (too long) & & * & \\
\hline d. [lan.ni:] & & & & & $*(\mathrm{n})$ \\
\hline e. [lein.ni:] & *! (lein.) & $*$ (too long) & & & $*(\mathrm{n})$ \\
\hline f. [lay.ni:] & & & $* !$ & & $*(\mathrm{y})$ \\
\hline
\end{tabular}

$\left(a_{c}\right.$ in SM is a central low vowel and $[a]$ is a front low vowel)

At the Perceptual Level, acoustic cues such as nasality may be perceived as well. SM has no phonemic nasal vowels but vowels are phonetically nasalized to various degrees before a nasal coda; therefore, inserting an extra nasal consonant improves the perceptual similarity between the perceived input and the loanword output. However, [len] in candidate (8b) is not a licit syllable in SM, [a] is therefore selected for a match. Candidate (8a) is ruled out by Mimic $\mathrm{V}_{\text {DURATION }}$ since [ac $\mathrm{a}_{\mathrm{c}}$ ] is long in an open syllable in the output and meanwhile it also violates MiMIC $\mathrm{V}_{\text {NASAL }}$. Candidate (8c) with the long vowel/diphthong [ei] violates MiMiC $\mathrm{V}_{\text {DURATION }}$, and it also violates Mimic $\mathrm{V}_{\text {Nasal }}$. Candidate (8e) is ruled out by OK- $\sigma$ by violating SM phonotactics. Although candidate (8f) has a short vowel and an inserted nasal, it violates the backness matching requirement between the corresponding vowels in the input and output. Candidate (8d) with nasal insertion is optimal since [an] retains the vowel duration, nasality and backness of the corresponding input vowel.

Some data we have collected outside the dictionary corpus (cf. footnote 3) show that when the English prenasal vowel is a low back stressed [a] in a trisyllabic word with the unstressed-stressed-unstressed stress pattern, nasal insertion does not occur. Tableau (9) presents the analysis of such an example

(9) Adaptation of Cabana [kə'bana]

\begin{tabular}{|c|c|c|c|c|}
\hline$/ \mathrm{ka}_{\mathrm{c}}: \mathrm{ba}_{\mathrm{c}}: \mathrm{na}_{\mathrm{c}}: / /$ & OK- $\sigma$ & MIMIC $V_{\text {DURATION }}$ & MIMIC $V_{\text {BACK }}$ & DEP-IO \\
\hline a. $\left[\mathrm{ka}_{\mathrm{c}}: . \mathrm{ba}_{\mathrm{c}}: \mathrm{na}_{\mathrm{c}}:\right]$ & & & & \\
\hline b. $\left[\mathrm{ka}_{\mathrm{c}}:\right.$ ban. $\left.\mathrm{na}_{\mathrm{c}}:\right]$ & & *! (too short) & * & $*(\mathrm{n})$ \\
\hline c. [ka $:$ bay. na $\left.a_{\mathrm{c}}:\right]$ & & *! (too short) & $*$ & $*(\mathrm{y})$ \\
\hline
\end{tabular}

According to our generalizations, an English intervocalic nasal triggers nasal insertion in SM loanwords when the prenasal vowel is stressed, lax, and nonhigh in English, so the lack of nasal insertion in this case is unexpected. We propose that the prenasal stressed [a] in this case is perceived as being long and/or tense. Green (2001) argues that $[a]$ in English can be lax and tense in different environments. He points out that all words in which [a] appears in contexts otherwise restricted to tense vowels are either loanwords like spa and mirage or hypocoristics like ma

\footnotetext{
${ }^{6}$ Hayes (2009) claims that the nasal consonants are considered ambisyllabic after both tense and lax vowels because of vowel nasalization. However, the current data show that prenasal lax vowels trigger a lot more nasal insertion in SM loanwords. Therefore, we propose that the phonetic cue of vowel duration is considered more important than vowel nasalization.
} 
and $p a$. Words in the our data like Cabana, Adana, Astana are foreign country names or exotic objects in English. If Green's claims are correct, the prenasal [a] is considered tense in the English source; hence nasal insertion does not apply. We therefore assume that the input vowels are perceived as being long on the assumption that stressed [a] is phonetically long or tense in open syllables in English, at least under appropriate lexical and/or prosodic conditions. The syllables of candidate (9a) have a better vowel duration match with the input; therefore, it is the optimal output, whereas candidates (9bc) are ruled out by both MIMIC constraints.

Our data also show examples of variable adaptation. In tableaux (10) and (11), an English trisyllabic word with the stressed-unstressed-unstressed pattern and a prenasal reduced vowel are adapted either with or without nasal insertion.

(10) Adaptation of Melanie ['meləni]

\begin{tabular}{|c|c|c|c|c|}
\hline /'me:lãni / & OK- $\sigma$ & MIMIC $\mathrm{V}_{\text {DURATION }}$ & MIMIC $V_{\text {NASAL }}$ & DEP-IO \\
\hline a. [mei.lan.ni:] & & & & * \\
\hline b. [mei.lr:.ni:] & & *! (too long) & * & \\
\hline
\end{tabular}

(11) Adaptation of Melanie ['meloni]

\begin{tabular}{|l|l|l|l|l|}
\hline$/$ 'me:Ir:ni:/ & OK- $\sigma$ & MIMIC V VURATION & MIMIC $V_{\text {NASAL }}$ & DEP-IO \\
\hline a. [mei.lan.ni:] & & $*$ ! (too short) & $*$ & $*$ \\
\hline b. [mei.Ir:.ni:] & & & & \\
\hline
\end{tabular}

This proposed analysis attributes the indeterminacy of nasal insertion in the outputs to different perceptual inputs. This idea is based on the likelihood that SM speakers are confused with the prenasal [ə] at the Perceptual Level since it is the phonetically shortest and most variable vowel in English. ${ }^{7}$ Therefore, the syllable / $/ \tilde{a} /$ with a short vowel as the input in (10) is good for duration compensation through nasal insertion. If [ə] is perceived short, nasal insertion is then necessary to form a closed syllable so as to maintain the bimoraic syllable weight in SM and also to have a better vowel duration match in SM loanwords. If [ə] is perceived as [r:] in an open syllable, as shown in (11), it is perfectly matched to [r:] in the output, so nasal insertion is not necessary.

In sum, the current analysis captures the important generalizations from the current dataset. OK- $\sigma$, MIMIC $V_{\text {BACK, }}$, MIMIC $V_{\text {DURATION, }}$, and MIMIC $V_{\text {NASAL }}$ are crucially ranked higher then DEP-IO to allow for nasal insertion. This analysis then suggests that this unnecessary repair is necessary on perceptual grounds (cf. Kang (2003) for Korean vowel insertion). The fact that under certain lexical and/or prosodic conditions, the prenasal stressed low back [a] does not trigger nasal insertion as expected and the unstressed [ə] in English exhibits variable adaptation in SM loanwords is attributed to different perceived inputs. These two cases need more investigation and are left for future research since it is also likely that vowel types and stress location may not be the only factors in determining how the source words are perceived or when nasal insertion applies.

\footnotetext{
${ }^{7}$ Informally, one native speaker of SM at the 2014 Phonology Conference informed us that she would only use the output form in (10) but not the other, another SM speaker would use the one in (11) but not the other, and the authors of this paper can use either form variably, suggesting the indeterminacy or confusion in this case. An experiment is currently underway to test our proposed claim.
} 


\section{Discussion and conclusion}

5.1. Discussion We have demonstrated that consonant adaptation in SM loanwords is not always a simple segment-to-segment matching process. Rather, as exemplified in this paper, the adaptation can be conditioned by phonetic and phonological factors related to the source language and the recipient language and how the borrowers may have constructed the input for the final phase of the adaptation process. Specifically, we have shown that vowel types and stress location in English are the two main conditions that determine whether nasal insertion applies in SM loanwords and suggested how the perceived inputs are represented in the adaptation process.

Miao (2005) shows that foreign nasals from Italian, German, and English are substituted by their corresponding nasals in Mandarin, i.e. /m, n, $\mathrm{y} /$. When deviations occur, the only feature that is likely to show variability is place. Changeability is found in coda positions due to SM phonotactic constraints. Hsieh, Kenstowicz and Mou (2009) further claim that the adaptation of nasals alters place of articulation based on the backness of the prenasal English nonhigh vowels. Their observations are in conformity to Lin's (2008) claim that matching the backness of the input and output vowels is crucial in the vowel adaptation process. The current study not only confirms SM's nasal adaptation patterns in the previous studies, but also identifies an additional pattern in which intervocalic nasals in English can be adapted with one or two nasals in SM loanwords depending on contextual factors, such as the vowel type and stress location in the English source words.

The so-called unnecessary nasal insertion is not random in SM loanwords since it can be attributed to phonological and phonetic factors. Phonologically, the English intervocalic nasal consonant between a stressed and an unstressed syllable can be analyzed as an ambisyllabic consonant since the prenasal vowel is nasalized. If this approach is adopted, one can suggest that English-SM bilingual speakers possess phonological input representation of English ambisyllabicity in a doubly linked structure (cf. LaChaité and Paradis 2005 on phonological input in loanword adaptation), and hence adapt such a doubly-linked nasal with two nasals linked to two syllables in SM loanwords through nasal insertion. If, on the other hand, SM speakers, especially those with low English proficiency, rely on the perception of the duration and nasality on the prenasal vowel, forming a closed syllable in the output through nasal insertion better matches the duration and nasality of the lax/short prenasal vowel. Our analysis presented in $\S 4.2$ is mainly based on the perceptual account, although it is conceivable to have a phonology-based analysis. Our proposal requires crucial assumptions on what the perceived inputs are. We assume that those SM speakers who are not fluent bilinguals perceive and retain the phonetic details, such as the duration and nasalization of the prenasal vowel in English, at the Perceptual Level. Native SM phonology then comes in to modify the relevant syllable to a grammatical one when necessary. By adopting Silverman's model to analyze the current data, we are able to take both phonology and phonetics into account.

Variable adaptation forms can also be attributed to the perceived input. Other than the anecdotal information mentioned in footnote 7, which confirms that both inputs in (10) an (11) for an English reduced vowel are possible, it was also brought to our attention that for some SM speakers the word Cabana analyzed in (9) can possibly be adapted as either $\left[\mathrm{ka}_{\mathrm{c}}: \mathrm{ba}_{\mathrm{c}}: \mathrm{na}_{\mathrm{c}}:\right]$ or $\left[\mathrm{ka}_{\mathrm{c}}:\right.$ ban.na $\mathrm{c}$ : $]$ depending on what the English prenasal low vowel is since in American English, for words like Rihanna, Cabana, and Astana, the prenasal vowel can be pronounced as either [æ] or $[a] .{ }^{8}$ This production difference may have influenced SM speakers' perception, leading to potential variable

\footnotetext{
${ }^{8}$ Thanks to Moria Yip (personal communication, 2014) for pointing this out.
} 
loanword forms in SM, e.g. Rihanna $\rightarrow$ [lei.ha $\left.\mathrm{c}_{\mathrm{c}}: \mathrm{na}_{\mathrm{c}}:\right] \sim$ [lei.an.na $\mathrm{a}_{\mathrm{c}}$ ]. The variation is predictable based on the proposed analysis since nasal insertion depends on what the perceived prenasal vowel is based on English vowel production. Another issue concerns the origin of the source words is English. For example, the words, such as Cabana and Astana, are not originally English words. It is hard to tell whether SM speakers borrowed them from English or from the original source languages; however, it does not matter where the words come from since our analysis predicts that the perceived input vary according to what the source vowel is. We, therefore, further maintain that the construction of perceived inputs are crucial in understanding loanword adaptation since they affect what the actual outputs are.

5.2. Conclusion We have demonstrated that nasal insertion in SM loanwords is conditioned by vowel types and stress location, and proposed that nasal insertion is principally motivated to improve the perceived similarity between the English input and the SM loanword output in terms of vowel duration and nasality. We conclude that this unnecessary repair is necessary due to the interaction between perception and syllable structure constraints of SM. Depending on who the adapters are, English phonology may also play a role. The unexpected and variable cases for English [a] and reduced vowels are hypothesized to have different perceived inputs constructed by SM speakers. We hope that future experimental studies can verify our proposed analysis in this paper.

English intervocalic singleton consonants may be adapted as geminate consonants in loanwords systems such as Japanese (Kubozono et al. 2008), Finnish (Karvonen 2005) and American Italian (Repetti 2009), in which stress and vowel types also appear to be relevant. In terms of the implication for the broader context, the fact that similar patterns occur cross-linguistically suggests a common basis that underlies consonant insertion/gemination in loanword adaptation.

\section{References}

Calabrese, Andrea., \& Wetzels, W. Leo. (Eds.). (2009). Loan phonology (Vol. 307). John Benjamins Publishing.

Duanmu, San. (2000/2007). The phonology of standard Chinese. Oxford: Oxford University Press.

Durvasula, Karthik., Huang, Ho-Hsin., \& Merrill, Rose. (2013). Word-internal ambisyllabic consonants are codas. The Journal of the Acoustical Society of America,134(5), 4201-4201.

Hayes, Bruce (2009). Syllabification in English, online: http://www.linguistics.ucla.edu/people/hayes/120a/HayesAmbisyllabicity.pdf.

House, Arthur. S. (1961). On vowel duration in English. The Journal of the Acoustical Society of America, 33(9), 1174-1178.

Hsieh, Feng-Fan., Kenstowicz, Michael., \& Mou, Xiaomin. (2009). Mandarin adaptations of coda nasals in English loanwords. Calabrese \& Wetzels (2009), 131-154.

Kang, Yoonjung. (2003). Perceptual similarity in loanword adaptation: English postvocalic word-final stops in Korean. Phonology, 20(02), 219-273.

Kang, Yoonjung. (2011). Loanword phonology. The Blackwell companion to phonology,4, 2258-2282.

Karvonen, Daniel. H. (2005). Word prosody in Finnish (Doctoral dissertation, University of California Santa Cruz).

Kawahara, Shigeto. (2007). Sonorancy and geminacy. In Leah Bateman, Michael O'Keefe, Ehren Reilly, and Adam Werle (eds.), University of Massachusetts Occasional Papers in Linguistics vol. 32: Papers in Optimality Theory III. Amherst: GLSA. $145-186$. 
Krakowt, Rena. A. (1994). Nonsegmental influences on velum movement patterns: Syllables, sentences, stress, and speaking rate. Haskins Laboratory Status Report on Speech Research, 31-48.

Kubozono, Haruo., Ito, Junko., \& Mester, Armin. (2008). Consonant gemination in Japanese loanword phonology. In 18th International Congress of Linguistics, Seoul.

LaCharité, Darlene., \& Paradis, Carole. (2005). Category preservation and proximity versus phonetic approximation in loanword adaptation. Linguistic inquiry, 36(2), 223-258.

Lin, Yen-Hwei. (2008). Variable vowel adaptation in Standard Mandarin loanwords. Journal of East Asian Linguistics, 17(4), 363-380.

Lovins, Julie. B. (1975). Loanwords and the phonological structure of Japanese. IULC.

Maddieson, Ian. (1984). Phonetic cues to syllabification. UCLA Working papers in phonetics, 59, 85-101.

Miao, Ruiqin. (2005). Loanword adaptation in Mandarin Chinese: Perceptual, phonological and sociolinguistic factors (Doctoral dissertation, Stony Brook University).

Peperkamp, Sharon., \& Dupoux, Emmanuel. (2003). Reinterpreting loanword adaptations: the role of perception. In Proceedings of the 15th international congress of phonetic sciences, 367-370. Barcelona.

Repetti, Lori. (2009). Gemination in English loans in American varieties of Italian. Calabrese \& Wetzels (2009), $225-240$.

Shih, Li-Jen. (2013). The adaptation of English vowel-nasal-vowel sequences in Mandarin loanword phonology. The $25^{\text {th }}$ North American Conference on Chinese Linguistics. Ann Arbor, MI

Shirai, Setsuko. (1999). Gemination in loans from English to Japanese (Master's thesis, University of Washington).

Silverman, Daniel. (1992). Multiple scansions in loanword phonology: evidence from Cantonese. Phonology, 9(2), 289-328.

Smith, Jennifer. L. (2006). Loan phonology is not all perception: Evidence from Japanese loan doublets. Japanese/Korean Linguistics, 14, 63-74.

Solé, Maria-Josep. (1992). Phonetic and phonological processes: The case of nasalization. Language and Speech, 35(1-2), 29-43. Umeda, Noriko. (1975). Vowel duration in American English. The Journal of the Acoustical Society of America, 58(2), $434-445$. Vendelin, Inga., \& Peperkamp, Sharon. (2006). The influence of orthography on loanword adaptations. Lingua, 116(7), 9961007.

Yip, Moira. (1993). Cantonese loanword phonology and Optimality Theory. Journal of East Asian Linguistics, 2(3), $261-291$.

Yip, Moira. (2002). Perceptual influences in Cantonese loanword phonology. Journal of the Phonetic Society of Japan, 6(1), 421.

新英漢辭典 [A New English English-Chinese Dictionary]. (1988). Ed. By the editing group of a New English-Chinese Dictionary. Seattle: University of Washington Press. 